\title{
A CONSTRUÇÃO DISCURSIVA DO ÓDIO NOS “CACEROLAZOS” (ARGENTINA) E NOS “PANELAÇOS" (BRASIL): PADRÕES COMUNS E DIFERENÇAS
}

\author{
The discursive construction of hate in "cacerolazos" (Argentina) and "panelaços" (Brazil): \\ common patterns and differences
}

La construcción discursiva del odio en “cacerolazos” (Argentina) y “panelaços” (Brasil): patrones $y$ diferencias comunes

Ramiro Carlos Humberto Caggiano Blanco ${ }^{1}$ Universidade de São Paulo

Yedda Alves de Oliveira Caggiano Blanco²

Universidade de São Paulo

\begin{abstract}
RESUMO
O trabalho objetiva mostrar como as expressões de ódio contidas nos enunciados proferidos nas manifestações contra o governo de Cristina Kirchner e de Dilma Rousseff, conhecidos como "Cacerolazos" (2012-2014) e "Panelaços" (2015-2016) representam e extremam o processo da construção desse sentimento. O corpus do trabalho é constituído por cartazes e depoimentos espontâneos dos participantes de ambas as manifestações, que serão analisados mediante comparações dos enunciados e apontamento das regularidades temáticas, discursivas e semióticas empregadas para expressar descortesia nos respectivos eventos políticos. $O$ uso do sentimento do ódio como recurso discursivo ultimamente parece ter sido utilizado em vários países como ferramenta política e, por tal razão, o estudo desse fenômeno se justifica na tentativa de poder compreendermos as semelhanças $e$ as diferenças de seu funcionamento. Na fundamentação teórica, usaremos os conceitos de descortesia por fustigação e de autonomia exacerbada dados por Marlangeon (2005), e a polarização ideológica "nós” x "eles" descrita por Van Dijk (2005). Veremos ainda como discursos símiles, por vezes especulares, foram realizados como expressão reativa a situações sociais nos dois países, mesmo que eles tenham formações sócio-históricas distintas, para finalmente, nas considerações finais, enfatizarmos o modo como a polarização foi construída.
\end{abstract}

Palavras-chave: Discurso do ódio. Descortesia. Ideologia. Cacerolazos. Panelaços.

\begin{abstract}
The objective of this work is to show how the expressions of hate speech contained in the statements made in the manifestations against the government of Cristina Kirchner and Dilma Rousseff, known as "Cacerolazos" (2012-2014) and "Panelaços" (2015-2016) represent this process. The corpus of the work consists of posters and spontaneous testimonies of the participants of both manifestations that will be analyzed through comparisons of the statements, pointing to the thematic, discursive and semiotic regularities used to express impoliteness in the respective political events. The use of hate sentiment as a discursive resource lately seems to have been used in various countries as a political tool and, for this

\footnotetext{
${ }^{1}$ Doutorando e Mestre em Língua Espanhola e Literatura Espanhola e Hispano-Americana pela Faculdade de Filosofia, Letras e Ciências Humanas, Universidade de São Paulo, Brasil; especialização em "Espanhol Ensino para Brasileiros" (Pontifícia Universidade Católica, São Paulo, Brasil) e em "Educação, Imagens e Mídia" (Faculdade Latino-

Americana de Ciências Sociais, Argentina). Foi professor do curso de Letras da Universidade São Marcos. Autor do livro "Gramática da língua espanhola: usos, conceitos e exercícios" e co-autor do livro "Formas de tratamento: português e espanhol em foco", entre outros. Universidade de São Paulo, orcid.org/0000-0001-7267-629, ramiro.caggiano@usp.br

${ }^{2}$ Doutoranda do curso de Letras da USP no programa de Filologia e Língua Portuguesa. Possui mestrado em Literatura Portuguesa, atuou no ensino superior nas áreas de Literatura, Linguística e Língua Inglesa. Participa dos grupos de pesquisa "Pragmática (Inter) linguística, cross-cultural e intercultural" (USP) e do grupo Es.Por.Atenuação/Brasil. Atualmente se dedica ao ensino de Língua portuguesa como LE. Universidade de São Paulo, orcid.org/0000-00034256-0703, yeddablanco@usp.br
} 
reason, the study of this phenomenon is justified in an attempt to understand the similarities and differences of its operation. In the theoretical foundation, we will use the concepts of impoliteness given by Marlangeon (2005), and the ideological polarization "Us" vs. "them" described by Van Dijk (2005). We will see how similar, sometimes mirror-like speeches have been performed as a reactive expression to social situations in both countries, even though they have different socio-historical formations, and finally, in the considerations, we emphasize the form in which the polarization is built.

Key words: Hate speech. Impoliteness. Ideology. Cacerolazos. Panelaços.

\section{RESUMEN}

El documento tiene como objetivo mostrar cómo las expresiones de odio contenidas en los enunciados realizados en las manifestaciones contra el gobierno de Cristina Kirchner y Dilma Rousseff, conocidas como "Cacerolazos" (2012-2014) y "Panelaços" (2015-2016) representan y extreman el proceso de construcción de tal sentimiento. El corpus de la obra está constituido por carteles y testimonios espontáneos de los participantes de ambas manifestaciones que se analizarán mediante comparaciones de los enunciados, señalando las regularidades temáticas, discursivas y semióticas empleadas para expresar descortesía en los respectivos eventos políticos. El uso del sentimiento de odio como recurso discursivo últimamente parece haber sido utilizado sistemáticamente en varios países como una herramienta política y, por esta razón, su estudio se justifica como un intento por comprender las similitudes y diferencias de su funcionamiento. Fundamentaremos teóricamente este trabajo empleando los conceptos de descortesía por fustigación y autonomía exacerbada de Marlangeon (2005), y la polarización ideológica "nosotros" $x$ "ellos" descriptos por Van Dijk (2005). También veremos cómo se fue posible la realización de enunciados tan semejantes, a veces especulares, como una expresión reactiva a situaciones sociales en ambos países, a pesar de tener formaciones sociohistóricas distintas y. finalmente, en las consideraciones, enfatizamos la forma en que se construyó tal polarización.

Palabras clave: Discurso de odio. Descortesía. Ideología. Cacerolazos. Panelaços.

Recebido em: dezembro 2019

Aceito em: dezembro 2019

DOI: $10.26512 /$ les.v20iespecial.29442

\section{INTRODUÇÃO}

Nicolau Maquiavel, no livro "O Príncipe”, considerado o texto precursor da ciência política, se perguntava se era mais conveniente ao governante ser amado ou temido. Dessa forma, estabelecia os sentimentos de amor e de temor como fonte de validação do poder do soberano, prescindindo da fundamentação teológica. Tais sentimentos foram, durante centúrias, os pilares dos estudos políticos até que, no século XX, se descobriu um bem mais funcional ao poder: o ódio.

Embora tenha havido, no passado século, muitas experiências políticas que aperfeiçoaram os mecanismos de controle social mediante a exacerbação do ódio contra determinados "outros", tanto em regimes políticos totalitários quanto em democráticos ${ }^{3}$, foi no século XXI que se alcançou o grau máximo de efetividade devido à presença ubíqua dos meios de comunicação e a entrada em cena de novos protagonistas: a internet e as redes sociais. O ódio encontrado nas interações se

\footnotetext{
${ }^{3}$ A respeito, é muito comum lembrarmos do nazismo, do stalinismo, e até do franquismo ou do falangismo, mas esquecermos do macartismo, por exemplo.
} 
assume, muitas vezes, como uma interface pela qual a realidade exterior é interpretada, mediante a busca da desconstrução ou da negação da narrativa do outro (antes do que afirmar a própria).

Diante disso, o presente trabalho tem como finalidade mostrar como as expressões de ódio contidas nos enunciados proferidos nas manifestações contra o governo de Cristina Kirchner e de Dilma Rousseff, conhecidos como "Cacerolazos" (2012-2014) e "Panelaços" (2015-2016), respectivamente, representam e extremam o processo de construção de tal sentimento. O corpus do trabalho é constituído por enunciados expressos em cartazes e por depoimentos espontâneos dos participantes de ambas as manifestações.

A partir das comparações dos enunciados, apontaremos as regularidades temáticas, discursivas e de elementos semióticos nos respectivos eventos políticos, tais como ataques à honra das ex-mandatárias - e membros dos partidos governantes-, à sua moral e sexualidade, o desejo tanático etc. seja mediante descortesia por fustigação, por refrateriadade, ou por exarcebação do “nós" (MARLANGEON, 2005) na polarização ideológica "nós” x “eles” (VAN DIJK, 2012). Por fim, veremos como discursos símiles, por vezes especulares, foram realizados como expressão reativa a situações sociais nos dois países, mesmo que eles tenham formações sócio-históricas distintas.

\section{A ARGUMENTAÇÃo NOS DISCURSOS DE ÓDIO}

Primeiramente, entendemos o discurso como "a materialização das formações ideológicas" (FIORIN, 2007, p.41), que colaboram para uma reprodução de índices discursivos no texto, na fala e na ação social em geral.

O discurso, segundo Van Dijk (2012), é visto como uma das partes da tríade cogniçãodiscurso-sociedade que opera as relações entre a língua e o poder. Ou seja, os participantes de um discurso, tanto falado como escrito, desempenham determinado papel social, marcado por uma formação ideológica, ideologias que, no dizer de Van Dijk (2005, p. 12),

têm uma função social [...] organizam e baseiam as representações sociais compartilhadas pelos membros de grupos (ideológicos). [...] são, em última instância, a base dos discursos e de outras práticas sociais dos membros dos grupos sociais como membros do grupo. [...] permitem que os membros organizem e coordenem suas ações (conjuntas) e suas interações com vistas aos objetivos e interesses do grupo como um todo.

Feitas tais observações, perguntamo-nos como os discursos de ódio se caracterizam argumentativamente? 
A argumentação, dentro da linha clássica, está voltada ao campo da lógica, da racionalidade apontada por uma premissa inicial e seu desenvolvimento com fatos, exemplificações, com o objetivo de resolver, esclarecer, convencer sobre um problema dado para uma determinada audiência (CEIA, 2009). Segundo o autor, "argumentar é procurar coerência onde existe dúvida, é descortinar sentido num paradoxo, mas também pode ser dar sentido a uma absurdidade ou a uma contradição" .

Entretanto, e aqui, entra o foco do nosso estudo, a argumentação nos atuais tempos expande os limites do discurso argumentativo clássico e adquire aspectos próprios. A primeira característica que apresentamos é a supremacia da emoção em detrimento da razão, pois

a argumentação crítica visa hoje inverter os termos da retórica clássica dos oradores gregos e romanos: o encantamento da opinião pública deve ser substituído pelo encantamento do leitor perante o texto; o poder do discurso oral, pelo poder significante do logos inscrito no texto autoral, ao qual sucede o poder significante do texto crítico; à verdade aparente detida pelo rhetor (CEIA, 2009).

Ao resignar a ordem racional da tônica argumentativa, temos um arguente, movido pela paixão ou não, que mira principalmente - por vezes, exclusivamente - o lado emocional da audiência, com o objetivo de provocar ou reforçar sentimentos para conseguir seu propósito. Assim, a argumentação pode-se diluir num mar de emoções que provocam um discurso difuso, cujo divórcio da realidade fatual se disfarça, amiúde, com matizes de ódio e preconceitos.

Como costumeiramente acontece nas ciências sociais com diversos termos, é muito difícil chegarmos a uma definição que seja aceita universalmente acerca do significado de "discurso do ódio" (WEBER, 2009).

$\mathrm{Na}$ necessidade de termos um conceito suficiente para dar conta deste trabalho, não trataremos do ódio individual, abordado pela psicologia, senão de sua manifestação social. Caracterizamos tal sentimento, seguindo Reguillo (2013), como uma prática social de construção "do outro", que se faz exacerbando a atribuição de diferenças intersubjetivas, de vários tipos, por mecanismos tais como aumentar as características negativas desse “outro", salientar desmedidamente as positivas do "eu", ou realizar uma combinação de ambas, que resulta em uma posição subalterna desse "outro" assim construído em relação ao indivíduo ou ao grupo que enuncia. Tal construção não só naturaliza a diferença como, no caso do ódio, faz desse "outro" um inimigo que ameaça, real ou potencialmente, a existência do "eu normalizador" do grupo. Como aponta Reguillo (2013), localizam “o diferente” nas antípodas da sociedade normalizada,

\footnotetext{
${ }^{4}$ CEIA, C. Verbete: argumentação. In: Dicionário de termos literários. Disponível em: http://edtl.fcsh.unl.pt/encyclopedia/argumentacao/. Acesso em: 11 jun. 2019.
} 
disciplinada e medicalizada, que se esforça para resistir às contaminações de um mundo "outro" que ameaça questionar seu sistema de doxas $^{5}$ constitutivo.

Dessa forma, a construção da "outredade" passa a ser um elemento constitutivo do "eu" do enunciador ou do grupo ao qual ele pertence ou ao qual ele, em maior ou menor medida, adere. Tal diferença, assim criada, é situada e relacional, ou seja, responde ao que e agora deve servir para infamar "o outro": xenofobia, misoginia, LGTBIfobia etc. Mas também, como veremos, pode se tratar de estigmatizações por motivos políticos.

A exacerbação de diferença assim criada modifica a dicotomia de Van Dijk "nós x eles" para uma crença-convicção ainda maior da impossibilidade de coexistir com esse "outro", que se expressa na fórmula “ou nós, ou eles". Muitas vezes, como veremos no corpus, o discurso de ódio serve para auto-vitimizar o "sujeito-odiante" mediante a acusação, direta ou velada, de que todos os males de que ele padece são consequência da existência desse "outro" ou de seus "privilégios", que considera insuportáveis. Tal fórmula chega ao ponto máximo quando os enunciados expressam literalmente o desejo de não-existência desse "outro", um desejo tanático que impossibilita toda compreensão da diversidade, da reflexão e do diálogo.

$\mathrm{O}$ aspecto mais grave na propagação desse tipo de discurso é que ele, muitas vezes, camufla-se de uma retórica aceita pela sociedade que, por exemplo, se embasa no direito à liberdade de expressão e que, amiúde, sob argumentos falazes, é simplesmente a atualização de preconceitos internalizados de longa data.

\section{O EFEITO DESCORTÊS DOS DISCURSOS DE ÓDIO}

A cortesia é uma norma social regulada por condutas que durante a interação busca prevenir e proteger a imagem dos interlocutores. Por outro lado, a partir do momento em que violamos as regras, colocando em risco a imagem do outro, temos a descortesia, que, segundo Culpeper (2011), pode ser consciente ou inconsciente. Segundo ele (2011, p. 19), “a descortesia ocorre quando: (1) o falante comunica intencionalmente o ataque à imagem, ou (2) o ouvinte percebe e/ou constrói o comportamento como intencionalmente de ataque à imagem, ou uma combinação de (1) e (2)"

Tanto nos estudos da cortesia como da descortesia (e, segundo Zimmermann (2005), também da "anticortesia") o conceito de imagem (face em inglês) apresenta um caráter central. A

\footnotetext{
${ }^{5}$ No original: "lo diferente" en las antípodas de la sociedad normalizada, disciplinada, medicalizada, que se esfuerza en resistir las contaminaciones de un mundo otro que amenaza con poner en cuestión el sistema de doxas [...].

${ }^{6}$ No original: Impoliteness comes about when: (1) the speaker communicates face-attack intentionally, or (2) the hearer perceives and/or constructs behaviour as intentionally face-attacking, or a combination of (1) and (2).
} 
esse respeito, os primeiros estudos foram iniciados por Goffman (1967[2011]) e retomados por Brown e Levinson (1978[1987]) na sua teoria da cortesia universal, criticada por autores de culturas não anglo-saxãs devido, entre outros problemas: a) ao risco de etnocentrismo ante a pretensão de universalidade de seus postulados; b) por deixar de fora da análise os atos que realçam a imagem do interlocutor; c) por não abordar o fenômeno da descortesia (BERNAL, 2005, p. 369) e da anticortesia; e d) por não dar devida atenção ao fenômeno da intensificação cortês. Estudos posteriores, como o de Bravo (1999), o de Kebrat-Orecchioni (1992), o de Briz (2004), o de Marlangeon (2005) e o de Albelda (2005), questionaram a universalidade da teoria brownlevisioniana e salientaram o papel do contexto sociocultural e da própria interação na proteção ou na ofensa à imagem. Assim, o presente artigo se alinha com essa visão mais ampla de compreensão da imagem.

O contexto, segundo Van Dijk (2012, p. 34), como conceito para o estudo das teorias da língua, deve partir do princípio de que é um construto subjetivo dos participantes, no qual as “situações sociais só conseguem influenciar o discurso através de interpretações (intersubjetivas) que delas fazem os participantes". O autor informa que esse construto faz parte de um modelo mental, individual, e não só situacional. Destarte, a compreensão do discurso "envolve a construção controlada pelo contexto, de modelos mentais baseados em inferências fundamentadas no conhecimento" (VAN DIJK, 2012, p. 92).

Assim, os modelos mentais são relevantes para a coerência do discurso, uma vez que são únicos e exprimem opiniões e emoções ao ativarem a memória individual e social, além de serem agentes formadores da identidade na construção do eu-mesmo e do ele-mesmo (VAN DIJK, 2012).

Nesse sentido, para entendermos a descortesia e sua dimensão, Marlangeon (2012) enfatiza que é preciso nos ater ao contexto, pois nem sempre o que se considera descortês em determinada situação comunicativa o é de fato. Quanto ao contexto, em nosso trabalho, importam-nos o geral e o do evento comunicativo específico, ou seja, aquele no qual foram proferidos os enunciados.

Neste estudo, tomaremos, da tipologia de descortesia proposta pela autora (2012, p. 10-14), dois conceitos, a saber:

A) A descortesia por fustigação ${ }^{7}$, representativa da atitude de ofensa deliberada proferida pelo locutor ao interlocutor e que busca o confronto no discurso. A autora a define como agressão verbal constituída em sua maioria por “comportamentos volitivos, conscientes e estratégicos”, cuja finalidade é de ferir a imagem do interlocutor como resposta a uma situação de enfrentamento ou desafio, ou como início dela.

\footnotetext{
${ }^{7}$ Como diz a autora, o termo fustigação é empregado no sentido metafórico de açoitar, de chicotear a imagem do interlocutor.
} 
Quando o discurso enfatiza o desrespeito extremo, rompendo as convenções sociais, estamos diante do ódio expresso que, ao estigmatizar o "outro", cria a exclusão de sujeitos ou de grupos sociais. Na descortesia por fustigação, quanto maior for o nível de lesão à imagem do destinatário, maior é a intensidade emocional do falante, "manifestada por certos indicadores de entonação e expressões verbais emocionais negativas" (MARLANGEON, 2017, p. 11).

Esse tipo de descortesia se caracteriza pela finalidade de "dominação ou intento de dominação", uma vez que, segundo a autora (2017, p. 13),

quien enfrenta, desafía o agrede al destinatario, lo hace desde la superioridad provocativa de pretender imponer su propia cosmovisión o requerimientos de imagen por sobre los del oyente, pues sin reclamo de poder, no hay descortesía.

B) Descortesia por excesso de afiliação ou afiliação exacerbada é uma variante proposta pela autora, na qual o conceito de descortesia dá-se quando "o adepto assume sua qualidade de membro com plena consciência e orgulho. Ele é a favor dos membros e das ideias de seu grupo, a ponto de escolher a descortesia em sua defesa." (MARLANGEON, 2005, p. 302).

No mesmo sentido, Van Dijk (2005, p. 27) aponta a criação, com fins antinômicos, do antagonismo maniqueísta entre "o nós" e "o eles", no qual o "nós" é depositário de todas as qualidades socialmente relevantes e o "eles" é privado destas.

\section{Metodologia, CORPUS E CONTEXTo}

O corpus para este estudo será formado pelos discursos de ódio, escritos e orais, de vídeos e de fotos de cartazes veiculados em várias revistas, sites e blogs que documentaram os eventos das manifestações ocorridas na Argentina, conhecidas como "Cacerolazos" (2013-2014), e das sucedidas no Brasil, denominadas de "Panelaços" (2015-2016).

Foram analisados 6 vídeos da Argentina, num total de 67'53”; e 9 vídeos do Brasil, num total de 38'29" das plataformas YouTube (06 da Argentina e 03 do Brasil) e Vimeo (02 no Brasil), e da rede social Facebook (04 do Brasil).

Desse modo, o método de análise é quantitativo com a seleção de enunciados de vídeos e de cartazes, bem como qualitativo, na medida em que a análise busca um eixo comum para explicar o fenômeno do ódio por meio das categorizações que foram explicitadas no item anterior.

\subsection{Contexto das manifestações "Cacerolazos" e "Panelaços"}

Quanto ao contexto sócio-histórico no qual as manifestações que analisaremos se desenvolveram, sumariamente apontaremos alguns paralelismos entre a Argentina e o Brasil: a) em 
matéria social, ambos os países criaram planos assistenciais para os setores mais desfavorecidos (Bolsa família e AUH); políticas de valorização do salário mínimo; criminalização do feminicídio; casamento igualitário; programas habitacionais (Minha casa, minha vida e PRO.CRE.AR); políticas de pleno emprego; criação de escolas e universidades etc.

b) no plano econômico: políticas de desendividamento externo; favorecimento do mercado interno para impulsionar o desenvolvimento econômico; política de crédito ativo para os setores produtivos etc.

c) na política exterior: diplomacia menos alinhada aos interesses dos EUA e mais voltada para a África e América Latina. Destacam-se a criação da UNASUL (União das Nações SulAmericanas) e da CELAC (Comunidade dos Estados Latino americanos e Caribenhos).

Diretamente ou não, muitas dessas realizações serão vistas como pontos negativos nos discursos das manifestações, como veremos oportunamente.

Referente ao contexto específico das manifestações na Argentina, logo após mobilizações protagonizadas por dirigentes agropecuários contrários a uma medida governamental, começaram a acontecer manifestações "autoconvocadas" por setores das classes alta e média alta de Buenos Aires, que foram se espalhando por outras capitais e grandes cidades, ao som do bater de panelas. Os motivos das reivindicações iam desde flexibilização da política cambial até reclamações por suposta falta de liberdade. Junto com o som das panelas apareceram manifestações de uma agressividade explícita tanto contra a presidenta Cristina Fernández quanto à agrupação política "La Cámpora", braço juvenil do partido governante. Essas manifestações alcançaram grau de massividade em 2012 e logo foram definhando paulatinamente. Foram conhecidas como \#13S \#8N \#18A \#8A \#13N y \#18F aludindo às datas de sua realização ${ }^{8}$.

Em 2015 e 2016, no Brasil, o mesmo tipo de manifestações ganhou as ruas também de capitais e de grandes cidades brasileiras, com o mesmo teor de agressividade contra a presidenta Dilma Rousseff e o Partido dos Trabalhadores. Embora alguns autores tentem estabelecer uma relação de causa-efeito entre essas mobilizações com as de 2013, elas tiveram protagonistas, objetivos e pautas reivindicatórias totalmente diferentes. Como explica o professor Calil (2016), nas primeiras

se colocaram em pauta demandas por ampliação da democracia, denúncia da repressão policial e reivindicação por direitos sociais e melhores serviços públicos. Em síntese, demandas de qualificação da democracia e em defesa do Estado social.

\footnotetext{
${ }^{8}$ Respectivamente: 13 de setembro e 8 de novembro de 2012; 18 de abril, 8 de agosto e 13 de novembro de 21013 , e 8 de fevereiro de 2014.
} 
Já nas segundas, conforme o autor, à defesa do impeachment misturaram-se "posições fascistizantes", de "regeneração da ditadura", hostilização pública da esquerda e mobilizações golpistas sob distintas formas, como a reivindicação por “intervenção militar”.

Por parte dos manifestantes - e até dos organizadores - dos dois países existiu um empenho imenso no plano da retórica, com o intuito de se apropriar de algumas das características dos movimentos sociais da África, da Europa e dos Estados Unidos, tais como Indignados, na Espanha, e Occupy, nos Estados Unidos. Uma das primeiras coisas que devemos apontar é que tinham algo em comum: desenvolveram-se em espaços públicos. Segundo Della Porta (2015, p. 15), no ano de 2011, em poucos meses apareceu em 3 continentes (África, Europa e América do Norte) uma forma de protesto que se desenvolvia, precisamente, nas praças. Quanto à centralidade do espaço público, Valdés (2015, p. 8) aponta que

en todos estos casos [...] los manifestantes ocupan el espacio público para transmitir sus reclamaciones en lugar de utilizar los mecanismos de intermediación política, esencialmente los partidos políticos, que son considerados elementos importantes de los sistemas democráticos. Por lo tanto, la protesta social es también indicación de una percepción que pasa por alto esos mecanismos y su rol en las democracias.

No plano estético desse ocupar o espaço também houve preocupação por se mimetizar como os movimentos sociais transatlânticos. Por exemplo, se na praça Tahrir, em El Cairo, Egito, só podiam estar as cores da bandeira daquele país, o mesmo aconteceu nas manifestações na Argentina e no Brasil, nas quais só apareceram símbolos pátrios, como bandeiras e camisetas de futebol por expresso pedido dos organizadores.

Figura 1 - Manifestações no Egito, Argentina e Brasil 'Ocupar o espaço'

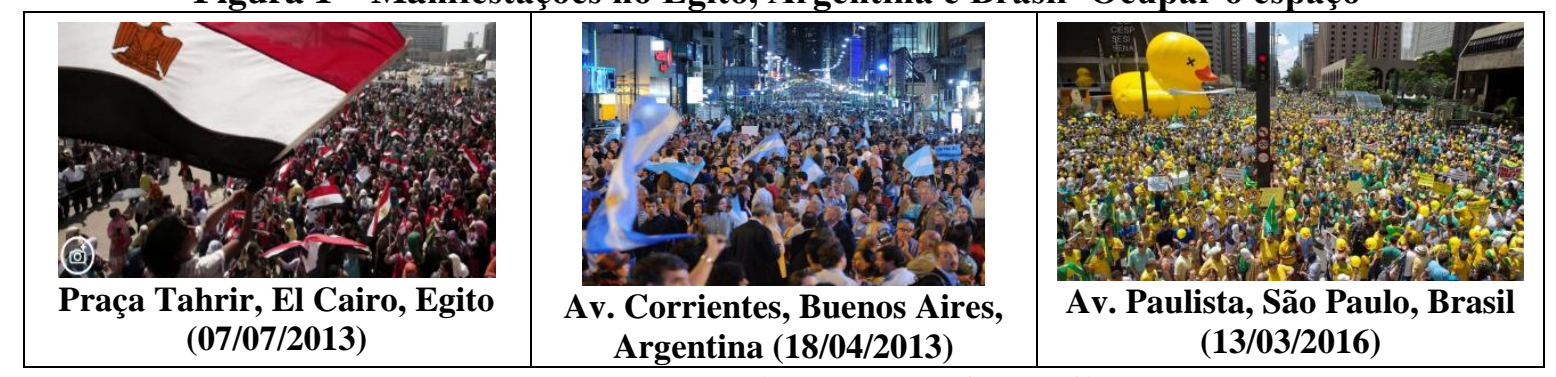

Fontes: Reuters, Clarín e Agência Brasil

Por outro lado, embora os organizadores das manifestações nos dois países proclamassem insistentemente o caráter de serem "autoconvocadas", sabia-se que isso não era real. O papel das redes sociais nas manifestações foi essencial nos dois países. Na Argentina participaram das convocatórias, da logística e da organização as páginas de Facebook: Yo no vote a la Kretina y Ud, Argentinos indignados, el Anti k, No más K, Unamos nuestros votos e El cipayo. A "independência” 
dessas páginas é muito questionável. $\mathrm{O}$ criador da página de Facebook el anti-K denunciou que a única manifestação realmente autoconvocada foi a primeira, já que depois a página foi cooptada por militantes do partido PRO, do atual presidente Mauricio Macri, prefeito de Buenos Aires à época.

No Brasil, as comunidades virtuais organizadoras das mobilizações tampouco eram transparentes. Uma das mais atuantes, o Movimento Brasil Livre - MBL -, foi uma marca "criada" pelo "Estudantes pela Liberdade" - EPL -, que recebia contribuições de organizações norteamericanas como Atlas e Student For Liberty, para, com este novo nome, "participar das manifestações de rua sem comprometer as organizações americanas”, que foram impedidas de doar recursos para ativistas políticos pela legislação impositiva de seu país de origem ${ }^{9}$.

Após a observação desses pontos contextuais, adentramos no caráter propriamente discursivo e na construção do ódio nos enunciados.

\subsection{Análise do corpus}

A partir do levantamento do corpus, como já detalhado, no presente artigo, a análise pretende observar os elementos comuns dos discursos de ódio que se desenvolvem nos dois eventos políticos sob estudo.

Apesar da dificuldade de se estabelecerem pontos em comum por se tratar de manifestações sui generis, que aconteceram em dois países diferentes e em tempos diferentes, a partir da análise dos discursos dos próprios manifestantes, coletados nas placas e em depoimentos espontâneos gravados, encontramos similitudes surpreendentes, conforme apontaremos.

Para os fins do presente trabalho, as categorizações da descortesia propostas por Marlangeon permitiram-nos organizar, apesar das diferenças, os elementos comuns nos enunciados de ódio nos dois países. Contudo, para um maior aprimoramento da análise, às duas categorias de descortesia de Marlangeon (descortesia por afiliação exacerbada e descortesia por fustigação) acrescentaremos subcategorias, propostas por nós, baseadas nas características comuns dos próprios enunciados descorteses do corpus.

\section{a) Descortesia por afiliação exacerbada}

a) i. Descortesia por afiliação exacerbada: sentimento de falta de justiça ou liberdade:

Nos seguintes casos, há um mecanismo de ataque ao Outro de forma mais indireta. De fato, exagerando os padecimentos de um “eu”, a contrario sensu, aumenta-se a acusação a "outro causador", supostamente, de seus infortúnios, como nos exemplos a seguir.

\footnotetext{
${ }^{9}$ Fonte: Revista Forum. Disponível em: http://www.revistaforum.com.br/2015/06/23/a-nova-roupa-da-direita/. Acesso em: 24 maio 2017.
} 


\begin{tabular}{|c|c|}
\hline Argentina & Brasil \\
\hline $\begin{array}{l}\text { "¿Por qué están acá? - Porque yo soy } \\
\text { argentino y yo sufro lo mismo que sufren } \\
\text { todos al no tener libertad” (V3-AR } \\
\mathbf{5 , 4 0 ” ) ~}\end{array}$ & $\begin{array}{l}\text { "Liberdade, liberdade pra você, pra mim } \\
\text { e fora o PT! Acabou PT, vai embora". } \\
\text { (V1-BR 4,20") } \\
\text { (placa) "Se não temos justiça o governo }\end{array}$ \\
\hline $\begin{array}{l}\text { "Estoy reclamando libertad, poder entrar } \\
\text { y salir de mi país, que ya no nos van a } \\
\text { dejar".(V4-AR 7,06") }\end{array}$ & não terá paz." (V7-BR 1,57") \\
\hline
\end{tabular}

Podemos perceber o uso das primeiras pessoas do plural e do singular ou a referência "pra mim" como caracterizadora desse "eu/nós" que, ao mesmo tempo, se auto-vitimiza e acusa o governo pela responsabilidade da sua situação.

a) ii. Descortesia por afiliação exacerbada: sentimento de falta de justiça econômica:

Uma variante da descortesia anterior que opera do mesmo modo é construída mediante a exacerbação de um "eu” que se sente injustiçado por ser quem, segundo sua própria percepção, contribui materialmente com o sustento econômico desse "outro":

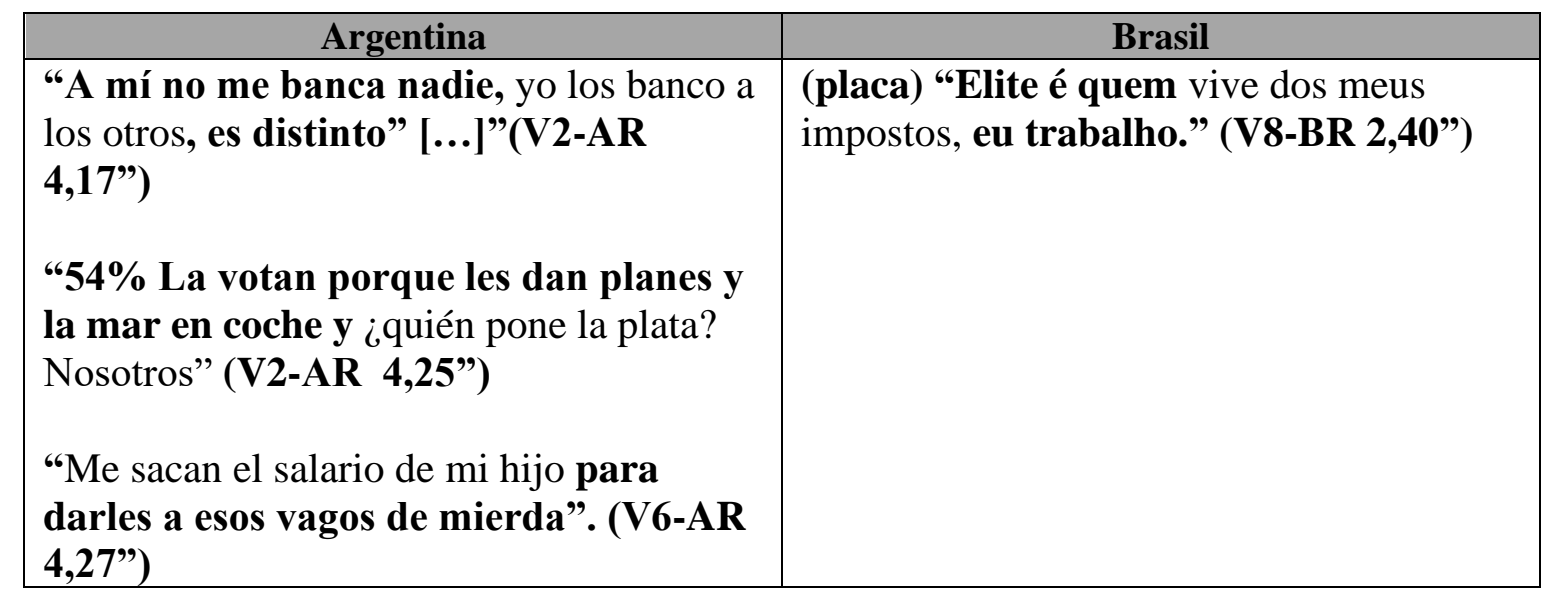

Desta forma, a construção do "eu" identitário dá-se mediante a exteriorização de uma suposta injustiça distributiva, segundo a qual ele seria quem carregaria o maior peso enquanto o "outro" seria o beneficiário de tal esforço.

\section{b) Descortesia por fustigação}

b) i. Descortesia por fustigação: ataque direto ao grupo por motivos econômicos

Mediante este mecanismo se ataca de forma direta o grupo que supostamente é favorecido pelo Governo. Um dos mecanismos empregados para tal efeito é a desqualificação sob acusação de clientelismo político. Dessa forma, mesmo que eles também possam se manifestar, esse "outro" 
assim construído não merece ser ouvido por carecer de vontade própria, agir movido por um choripán y planes sociales ${ }^{10}$ ou por um sanduíche de mortadela e bolsa família, como se aprecia nos seguintes depoimentos:

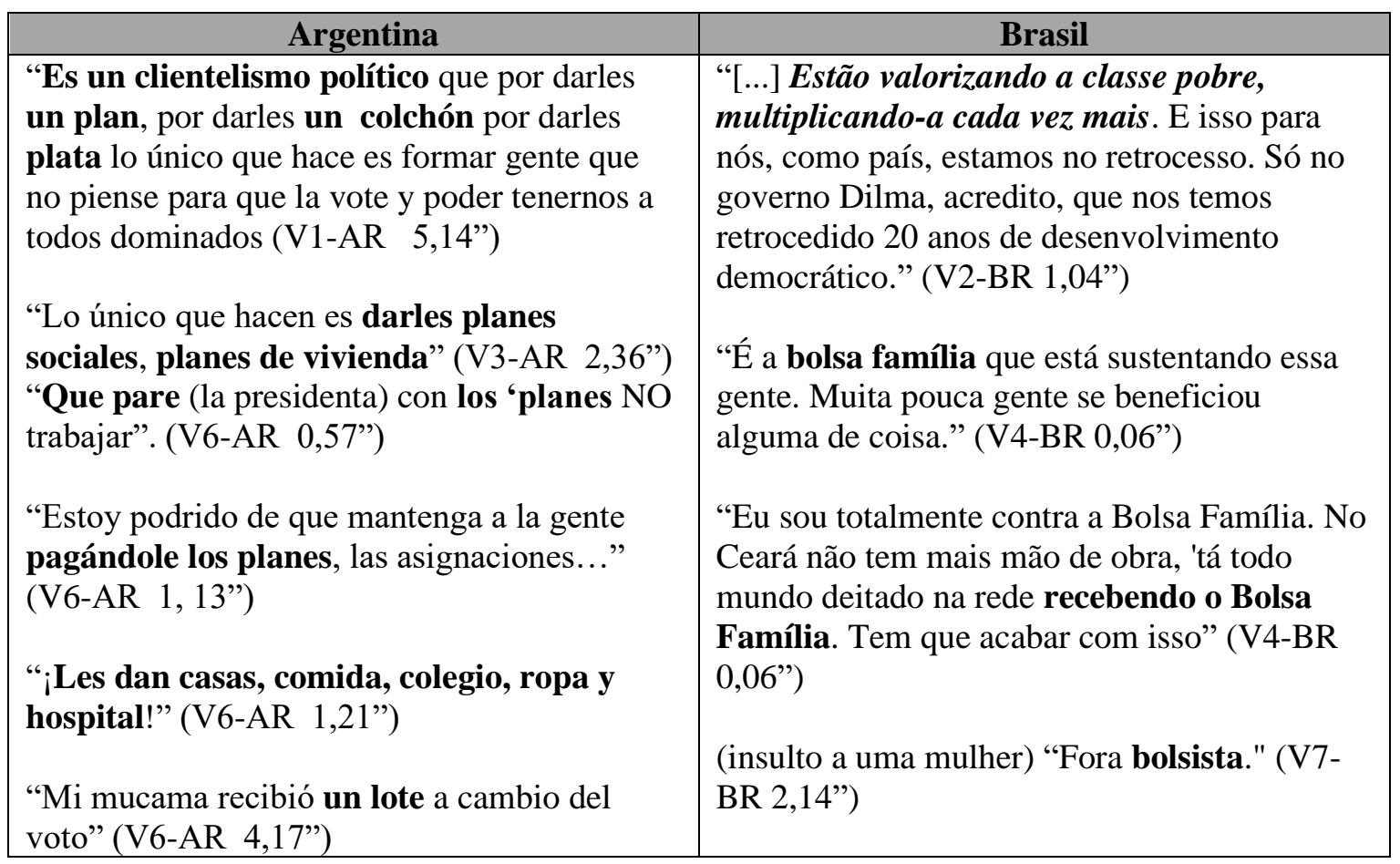

b) ii. Descortesia por fustigação: desqualificação direta ao grupo e às mandatárias mediante ataque à honra

Como vimos, o discurso de ódio se instaura porque há uma necessidade de distinção do "eu" com o "outro" que visa a alterar o mecanismo de dominação sistêmica. No caso das manifestações contra Dilma Rousseff, como explica Sampaio (2015), a principal reivindicação era a luta contra a "corrupção seletiva" do PT. O mesmo pode se aplicar aos manifestantes argentinos. A corrupção serviu como um cavalo de Tróia para ocultar, de início, o sentimento de ódio às mandatárias e ao grupo que representam, entre outros mecanismos discursivos, por meio de desqualificações à honra.

\footnotetext{
${ }^{10} \mathrm{Na}$ Argentina, "choripan” é o nome dado a um sanduíche de linguiça (chori= chorizo + pan), e o vendedor de tal sanduiche é chamado de "choripanero". Ainda chegou a ser acunhado o apelido de "choriplanero" para referir aos eleitores peronistas, justapondo as duas características atribuídas a eles: de serem supostamente levados às manifestações para comer "choripan" e a de votarem no governo em troca de "planes sociales".
} 


\begin{tabular}{|c|c|}
\hline Argentina & Brasil \\
\hline $\begin{array}{l}\text { “Corruptos, inmorales” [...]”(V2-AR, 4,04”) } \\
\text { “Que se vaya Cristina, yegua.” (V 6, 0,25) } \\
\text { “Andate a Angola, la puta que te pariô” (V1- } \\
\text { AR 4,41”) } \\
\text { “Joder a la atorranta esa que nos está } \\
\text { gobernando, esa sinvergüenza, esa ladrona” } \\
\text { (V3-AR 4,22”) } \\
\text { “Andá con Néstor, la puta que te parió } \\
\text { (cantando todos)” (V4-AR 2,20”) } \\
\text { (placa) “ i¿Donde estás yegua?!” (anexo) }\end{array}$ & $\begin{array}{l}\text { “E leva o Lula junto, e os vagabundos do PT” } \\
\text { (Piauí) } \\
\text { “Ajuda! Vamos tirar os bandidos do poder. } \\
\text { Não é só Dilma, é todos! Todos são uns } \\
\text { bandidos. Chega! Basta!”. (V1-BR 4,56”) } \\
\text { (placa) “CorruPTos" (V2-BR 2,02”) } \\
\text { "E não vamos admitir uma guerra. Nós não } \\
\text { admitimos mais guerra civil. Eles tem que cair } \\
\text { fora numa boa, malandro que são.” (V3-BR } \\
\text { 2,20”) } \\
\text { (placa) "Fora Dilma mentirosa, Petralhas } \\
\text { malditos.” (V2-BR 3,02”) } \\
\text { “Filhos Dilma PuTa” (Piauí) }\end{array}$ \\
\hline
\end{tabular}

É importante destacar, nesse conjunto de manifestações, a preocupação que houve em associar as letras que identificam os grupos governantes alvos dos ataques, com a corrupção mediante elementos semióticos. Assim, apareceram placas com a modificação da palavra "corruptos" por "Korruptos", em clara referência aos "K", como se conhece a corrente ideológica do partido justicialista iniciada pelo casal Kirchner. No Brasil, para conseguir similar efeito, destacaram-se as letras PT da palavra "CorruPTos", para se associar à ideia de corrupção com a sigla do Partido dos Trabalhadores.

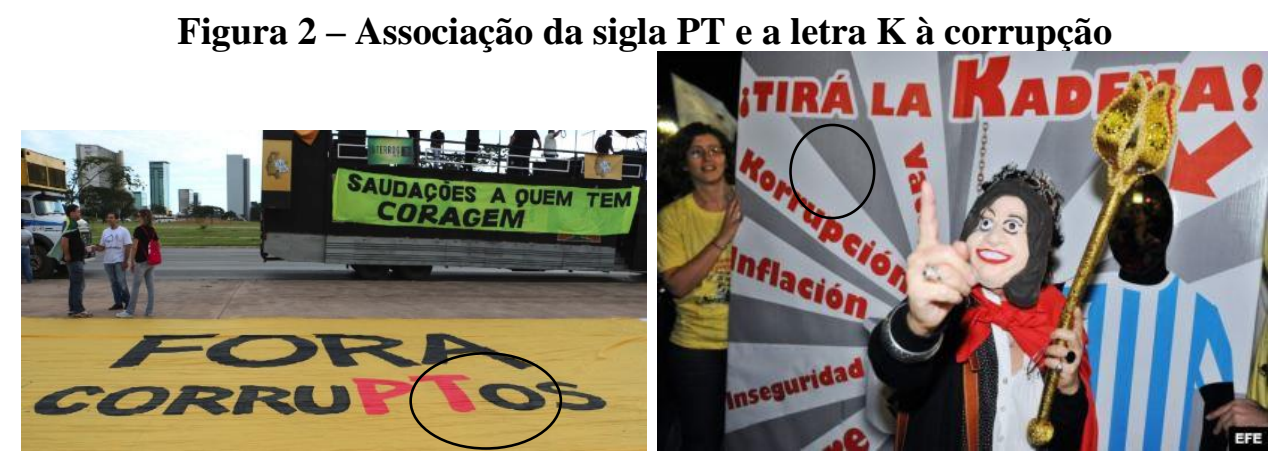

Fontes: https://noticias.uol.com.br e https://www.radiotelevisionmarti.com

b) iii. Descortesia por fustigação: ataque direto à honra sexual das mandatárias

Em outros discursos, sempre com o mesmo propósito de destruição da imagem do outro, a descortesia por fustigação se expressa mediante ataques de teor sexual, muitas vezes misóginos:

\begin{tabular}{|c|c|}
\hline Argentina & Brasil \\
\hline (cántico) “Cristina conchuda vos sos la & (coro) "Ei, Dilma, vai tomar no cu.” (Piauí) \\
\hline
\end{tabular}




\begin{tabular}{|c|c|}
\hline $\begin{array}{l}\text { dictadura" (V1-AR 2,55") } \\
\text { "Yo me quiero ir todos los años de viaje a } \\
\text { Punta del Este pero esta negra puta no me } \\
\text { deja". (V4-AR 0,45") } \\
\text { "Agarrame ésta, Cristina (aludiendo a su } \\
\text { vagina)" (V4-AR 0,52") } \\
\text { (cântico) "Es para vos, es para vos, Cristina } \\
\text { puta la puta que te parió". (V4-AR 9,00") }\end{array}$ & $\begin{array}{l}\text { (V6-BR 3,16”) (V1-BR 0,52”) } \\
\text { (cântico) “Quem se habilita, comer a Dilma } \\
\text { sem birita.” (V5-BR 0,05”) } \\
\text { (placa) "Dilma, pare de ferrar o Brasil e vai } \\
\text { transar.” (V5-BR 0,14”) } \\
\text { (cântico) “A Dilma quer transar, quem se vai } \\
\text { arriscar? lá lá lá Vota pra fuder.” (V5-BR } \\
\text { 0,34”) } \\
\text { (coro) "Chupa PT." (V8-BR 6,45”) } \\
\text { (placa) Dilma com dedo no cu do povo } \\
\text { (placa) Lula já comi sua mãe } \\
\text { (placa) "Dilma sua putinha" }\end{array}$ \\
\hline
\end{tabular}

Figura 3 - Ataque à honra

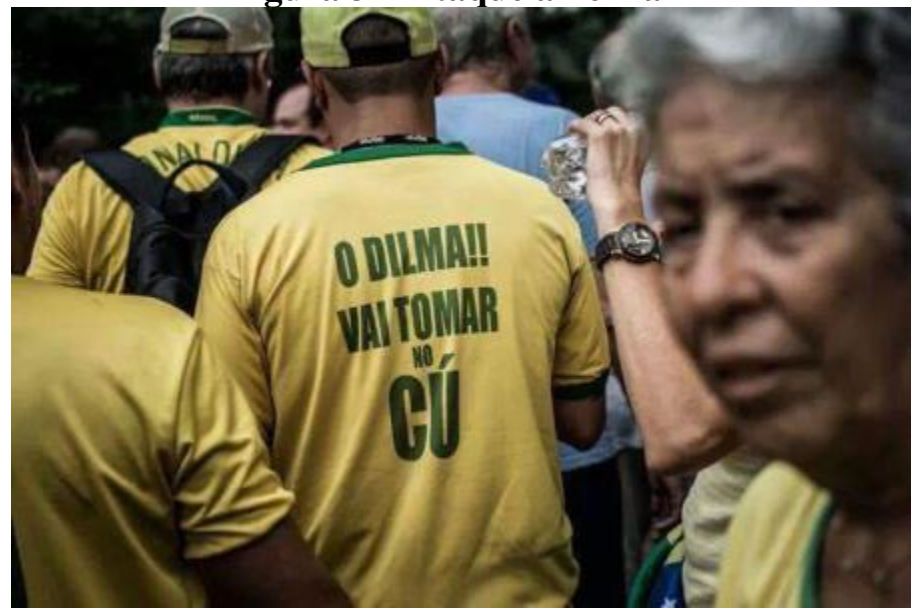

Fonte: https://luizmuller.com

b) iv. Descortesia por fustigação: acusação ao governo de totalitarismo ou comunimo

\begin{tabular}{|c|c|}
\hline Argentina & Brasil \\
\hline $\begin{array}{l}\text { "[...] estamos hartos de los fachos del } \\
\text { gobierno[...]"(V2-AR 1,14") }\end{array}$ & $\begin{array}{l}\text { (2 placas) "Fora impostos destrutivos / Fora } \\
\text { comunismo" (V1-BR 4,33") (símbolo nazista } \\
\text { no I de comunismo) }\end{array}$ \\
\hline $\begin{array}{l}\text { "Son unos boludos esos del gobierno" }[\ldots] \\
\text { Esto es facismo" [...]" (V2-AR 1,17") }\end{array}$ & $\begin{array}{l}\text { (coro) “Quem não pula é comunista". (V2-BR } \\
0,22 ”) \text { (V8-BR 6,38”) }\end{array}$ \\
\hline $\begin{array}{l}\text { "Esto no es una democracia, esto es una } \\
\text { tiranía oculta" (V3-AR 4,50") }\end{array}$ & $\begin{array}{l}\text { (placa) “Comunismo aqui não.” (V7-BR } \\
1,20 ”)\end{array}$ \\
\hline $\begin{array}{l}\text { "Una dictadura de mediocres” (V3-AR } 0,30 ”) \\
\text { “No es democracia” (V3-AR 0,37”) } \\
\text { “Esto no es una dictadura, acaso? ¿Esto no } \\
\text { es una dictadura?”(V3-AR 3,31”) }\end{array}$ & $\begin{array}{l}\text { "A organização internacional, FHC, Dilma } \\
\text { Rousef, Lula, Fidel Castro, Puttin, comunismo } \\
\text { é uma organização criminosa internacional." } \\
\text { (V3-BR 0,06”) }\end{array}$ \\
\hline
\end{tabular}


Esto es una dictadura, no es una democracia". (V4-AR 0,59")

(cántico) "Se a acabar, la dictadura de los K" (V2-AR 1,06") e (V4-AR 1,32")

"Este gobierno no es ni representativo, ni republicano, ni federal que dice la Constitución Nacional en su artículo 1 que es la forma de gobierno que adopta la nación". "Los milicos no son nada al lado de esto..."[...]"(V2-AR 3,57")
"Eles estão intentando impor um regime que não é o democrático." (V2-BR 1,02")

"Quero que o PT saia porque os amigos do PT são todos ditadores de esquerda querendo, 'tão enganando a população querendo implantar um regime COMUNISTA no Brasil [...]" (V2-BR 0,25”)

(reza) "[...] e não nos deixeis cair em tentação, mas livrai-nos do mal -e do terrorismo!, amém" (V1-BR 0,37")

O primeiro que se aprecia é que o sentimento de opressão na Argentina se manifesta, principalmente, pelos significantes "tiranía" e "dictadura", enquanto no Brasil, pela palavra "comunismo".

As palavras "ditadura", "tiranía", falta de "democracia", “comunismo", "terrorismo" etc., como demonstram os exemplos anteriores, estabelecem uma distinção entre um "nós vitimizado" que suporta o regime opressivo, e um "eles opressor ou tirânico" ("Los K” na Argentina e "Os Petralhas" no Brasil). O discurso, desse modo, carrega-se de afirmações negativas da atuação do "outro" que se traduz em acusações desqualificatórias que, como aponta Marlangeon, constituem descortesia por fustigação. Segundo a autora (2012), a descortesia por fustigação confronta o "outro" com a intenção de acusar, de menosprezar.

Uma variante do recurso anterior dá-se mediante o uso de significantes semelhantes, do ponto de vista dos enunciadores, o comunismo e a ditadura, no caso, em referência a Cuba e à Venezuela. Entretanto, apesar de tal mudança, a produção de sentido se dá pelos mesmos mecanismos: um "nós auto-vitimizado" versus um "outro opressor", como podemos perceber nos enunciados a seguir:

\begin{tabular}{|c|c|}
\hline $\begin{array}{r}\text { Argentina } \\
\end{array}$ & Brasil \\
\hline $\begin{array}{l}\text { (placa) "No queremos Venezuela" } \\
\text { “[ ...] que esto no es Venezuela ni Cuba". } \\
\text { (V6-AR 0,58") } \\
\text { "[ ...] esto va a ser peor que Cuba, que } \\
\text { Venezuela, que Corea del Norte" (V3-AR } \\
1,58 ”)\end{array}$ & $\begin{array}{l}\text { (placa) “Não! a venezualização do Brasil!” } \\
\text { (V1-BR 0,07”) } \\
\text { “[...] aqui é o Brasil, aqui não é Venezuela, } \\
\text { não é Cuba” (V2-BR 0,41”) } \\
\text { (placa) "Maduro genocida / Venezuelano, } \\
\text { apoia Dilma / Fota PT!!!” (V7-BR 0,57”) } \\
\text { (placa) “Dilma pegue seu cartão vermelho } \\
\text { (letras em vermelho) e vá governar em Cuba q } \\
\text { pariu (letras em vermelho).” (V7-BR 1,14”) } \\
\text { (arenga) "Viva o Brasil! Fora Cuba, fora }\end{array}$ \\
\hline
\end{tabular}




\section{Venezuela, fora o PT!" (V7-BR 1,37”)}

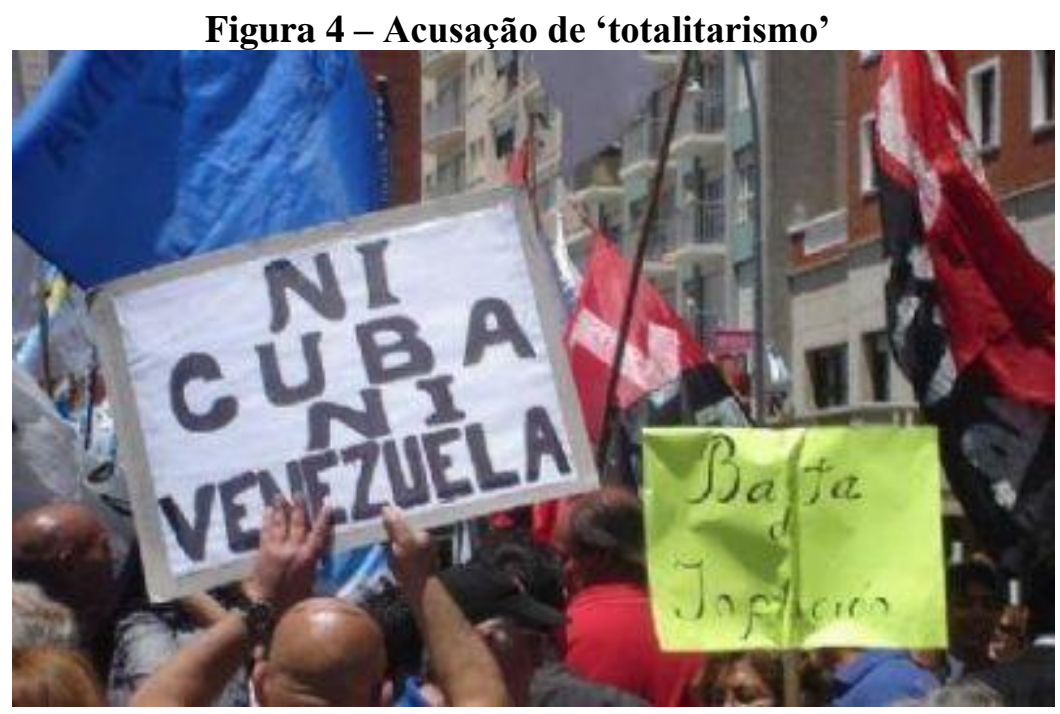

Fonte: http://www.treslineas.com.ar

Notamos que, no caso dos enunciados brasileiros, eles diretamente manifestaram uma associação entre os termos "Cuba" e "Venezuela", e seus derivados, com a presidenta Dilma e o Partido dos Trabalhadores, enquanto tal associação com a presidente Cristina Kirchner, nos enunciados dos argentinos, foi mais implícita.

b) v. Descortesia por fustigação: desejo tanático

Finalmente, encontramos a descortesia extrema expressada por um desejo tanático que significa simplesmente o desejo da aniquilação do "outro", o desejo da não existência:

\begin{tabular}{|l|l|}
\hline \multicolumn{1}{|c|}{ Argentina } & \multicolumn{1}{|c|}{ Brasil } \\
\hline $\begin{array}{l}\text { "(mirando al cielo) Néstor (Kitchner), } \\
\text { llevala" (V6-AR 0,38") }\end{array}$ & $\begin{array}{l}\text { (placa) "Comunista é bom morto/ Dilma, } \\
\text { Maduro, Hugo, Fidel, Cristina, Lula / Lixo do } \\
\text { mundo" (anexo) }\end{array}$ \\
$\begin{array}{l}\text { "Podía volver (Néstor Kitchner) y llevar a su } \\
\text { esposa". (V6-AR 0,40") }\end{array}$ & $\begin{array}{l}\text { (placa) "Dilma go to hell Chávez is waiting } \\
\text { for you!" }\end{array}$ \\
$\begin{array}{l}\text { "Cuando se haga un botox, ojalá la aguja se le } \\
\text { piante y se le vaya para otro lado". (V6-AR } \\
0,47 ")\end{array}$ & \\
$\begin{array}{l}\text { "Andá con Néstor, la puta que te parió } \\
\text { (cantando todos)" (V4-AR 2,20") }\end{array}$ & \\
(Placa) "Muerte a los K y a Moreno" (V6- & \\
\hline
\end{tabular}




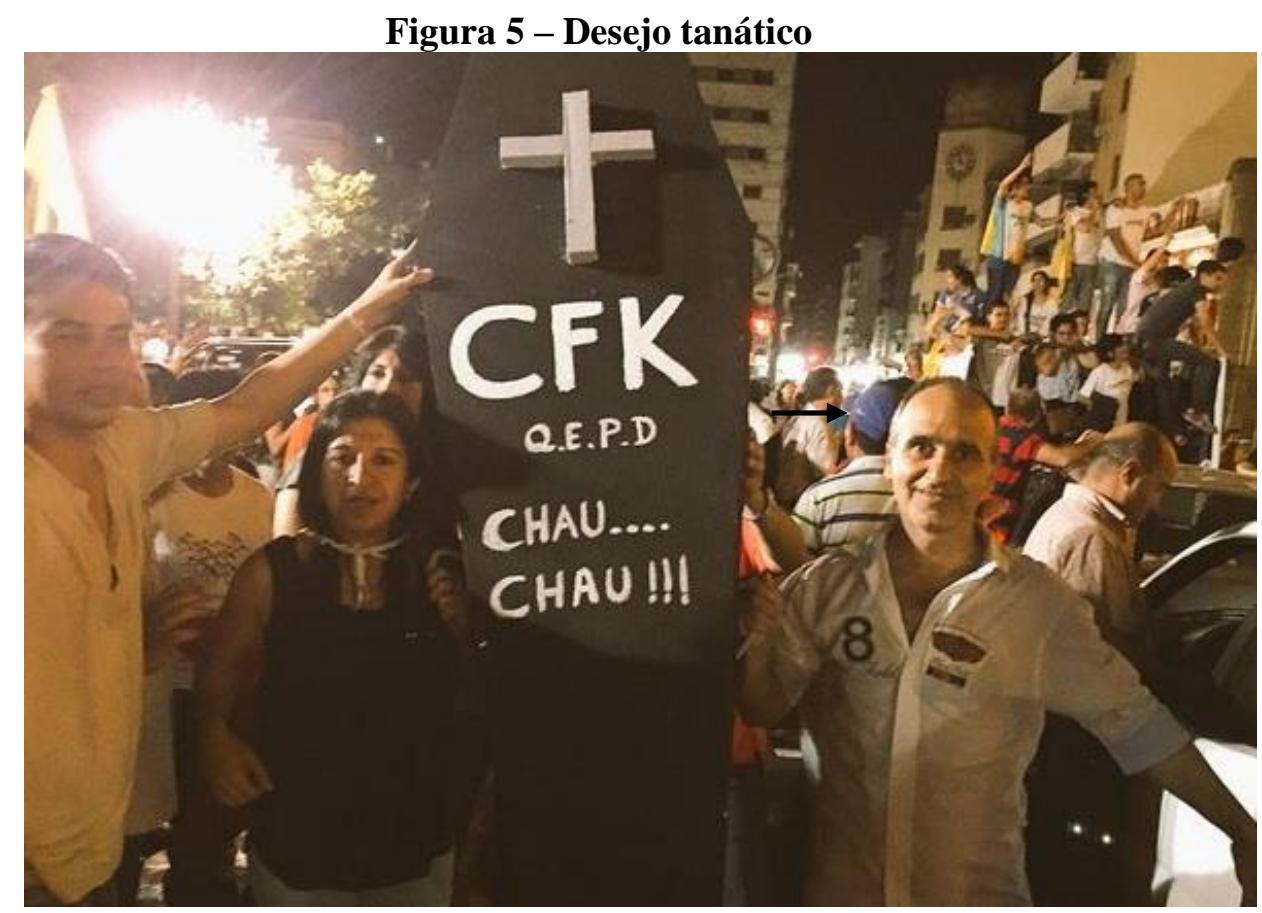

Fonte: https://www.diarioregistrado.com

\section{CONSIDERAÇÕES FINAIS}

Tínhamos como objetivo mostrar como as expressões de ódio contidas nos enunciados proferidos nas manifestações contra o governo de Cristina Kirchner e de Dilma Rousseff, conhecidos como "Cacerolazos" (2012-2014) e "Panelaços" (2015-2016), tentaram se apropriar de certo tipo de discurso, no caso o de ódio, para operar de forma a usar a emoção, e não a eloquência racional para a imposição de pautas argumentativas de teor político e social.

O discurso de ódio mostrou-se como um reprodutor ideológico de formas e conteúdos marcados por atitudes e crenças consolidadas, muitas vezes estereotipadas, da apropriação histórica dos países em questão. Assim, ao percebemos a dicotomia, pautada por Van Dijk, entre o “nós” e “eles", vimos nos discursos apresentados o reforço de uma divisão, marcada linguisticamente, por termos que separam, segregam ou dividem os interlocutores.

Vimos também que se repetiram, nas manifestações em ambos os países, os mesmos tipos de argumentos empregados para articular enunciados descorteses, a mesma gramática das imagens e, por vezes, até os mesmos significantes, com estruturas linguísticas muitas vezes especulares.

Dessa forma, observamos o emprego de modo distópico de significantes como: “comunista", "Cuba", "Venezuela" etc. como sinônimos de ditadura, falta de liberdade e opressão. Também, mediante autovitimizações (descortesia por afiliação exacerbada) ou acusações a um "outro" (descortesia por fustigação) de ser a causa dos próprios males, supostamente por usufruir sem direito de benefícios sociais à custa dos enunciadores. Nessa última estratégia de descortesia, 
merecem especial menção os ataques à honra das mandatárias, chegando ao ponto de configurarem agressões de teor sexual. Por fim, chega-se ao grau máximo de ódio nos enunciados que expressam o desejo da não existência do "outro".

Por tudo isso, tanto a ira contra as mandatárias quanto o sentimento de injustiça autoatribuído por suposta falta de liberdade ou por injusta divisão dos bens materiais nos possibilita concluir que o fio comum que organizou simbolicamente e deu sentido político às manifestações de "caceroleros" e de "paneleiros" foi um sentimento de ódio que exacerbou o "eu" e, ao mesmo tempo, deslegitimou a existência do "outro".

\section{REFERÊNCIAS BIBLIOGRÁFICAS}

ALBELDA, M. Discordancia entre atenuación/cortesía e intensificación/descortesía en conversaciones coloquiales. In: BLAS, J. L.; CASANOVA, M.; VELANDO, M. (ed.). Discurso y sociedad. Contribuciones al estudio de la lengua en contexto social. Castellón: Servicio de publicaciones de la Universidad de Castellón, 2005. p. 581-590.

BERNAL, M. Hacia una caracterización sociopragmática de la cortesia, la descortesía y la anticortesía. In: BRAVO D. (ed.). Estudios de la (des)cortesía en español: categorias conceptuales y aplicaciones a corpora orales y escritos. Buenos Aires: Editorial Dunken; 2005.

BRAVO, D. ¿Imagen positiva vs. imagen negativa?: Pragmática social y componentes de la face. Oralia, n. 2, p. 155-184, 1999.

BRIZ, A. Cortesía verbal codificada y cortesía verbal interpretada en la conversación. In: BRAVO, D.; BRIZ, A. (ed.). Pragmática sociocultural: estudios sobre el discurso de cortesía en español. Barcelona: Ariel, 2004.

BROWN, P.; LEVINSON, S. C. Politeness. Some universals in language use. Cambridge: Cambridge University Press, 1987 [1978].

CALIL, G. Reflexões sobre a ascensão da direita. In: Junho Blog, 06/maio/2016. Disponível em: http://blogjunho.com.br/reflexoes-sobre-a-ascensao-da-direita/. Acesso em: 25 maio 2017.

CEIA, C. Verbete: argumentação. In: Dicionário de termos literários. Disponível em: http://edtl.fcsh.unl.pt/encyclopedia/argumentacao/. Acesso em 11 jun. 2019.

CULPEPER, J. Impoliteness: using language to cause offence. Nova York: Cambridge University Press, 2011.

DELLA PORTA, D. Prácticas democráticas en los movimientos antiausteridad: De foros a campamentos, de América Latina a Europa. In: Protestas Sociales y Capacidad de Respuesta de la Democracia: Evaluando Realidades en América Latina y el Caribe y la Unión Europea. Fundação EU-LAC: Hamburgo, 2015. Disponível em: https://eulacfoundation.org/es/system/files/Protestas_Sociales_esp.pdf. Acesso em: 01 maio 2017.

FIORIN, J. L. Linguagem e ideologia. 8. ed. São Paulo: Ática, 2007. 
GOFFMAN, E. Ritual da interação. Tradução: Fábio Rodrigues Ribeiro da Silva. Petrópolis, RJ: Vozes, 2011[1967].

KEBRAT-ORECCHIONI, C. Les interactions verbales. Vol. II. Paris: Armand Colin, 1992.

MARLANGEON, S. K. Descortesía de fustigación por afiliación exacerbada o refractariedad. In: D. BRAVO (org.). Estudios de la (des) cortesía en español. Categorías conceptuales y aplicaciones a corpora orales y escritos. Buenos Aires: Dunken, 2005.

MARLANGEON, S. K. Encuadre de aspectos teóricos-metodológicos de la descortesía verbal en español. In: MORALES, J. E.; VEGA, G. H. (org.). Miradas multidisciplinares a los fenómenos de cortesia y desortesía en el mundo hispânico. Barranquilia, Estocolmo: Cadis, Programa Edice, 2012. p. 76-106.

MARLANGEON, S. K. Tipos de descortesía verbal y emociones en contextos de cultura hispanohablante. In: BRAVO, D. Pragmática Sociocultural /Sociocultural Pragmatics: Revista Internacional sobre Lingüística del Español, Edice, 2017. Disponível em:

https://www.degruyter.com/view/j/soprag.ahead-of-print/soprag-20170001/www.degruyter.com/view/j/soprag.ahead-of-print/soprag-2017-0001/soprag-2017-0001.xml. Acesso em: 21 nov. 2017.

REGUILLO, R. Políticas de la (In)visibilidad: La construcción social de la diferencia. Buenos Aires: Flacso Virtual, 2013.

SAMPAIO, A. Reivindicaciones y conectividad en las protestas de Brasil. In: Protestas Sociales y Capacidad de Respuesta de la Democracia: Evaluando Realidades en América Latina y el Caribe y la Unión Europea. Fundação EU-LAC: Hamburgo, 2015. Disponível em:

https://eulacfoundation.org/es/system/files/Protestas_Sociales_esp.pdf. Acesso em: 01 maio 2017.

VALDÉS, J. Protestas Sociales y Capacidad de Respuesta de la Democracia: Evaluando Realidades en América Latina y el Caribe y la Unión Europea. In: Protestas Sociales y Capacidad de Respuesta de la Democracia: Evaluando Realidades en América Latina y el Caribe y la Unión Europea. Fundação EU-LAC: Hamburgo, 2015. Disponível em:

https://eulacfoundation.org/es/system/files/Protestas_Sociales_esp.pdf. Acesso em: 01 maio 2017.

VAN DIJK, T. A. Ideología y análisis del discurso. In: Utopia y Praxis Latinoamericana. Maracaibo: Universidad del Zulia, 2005, p. 9-36. Disponível em: http://www.discursos.org/oldarticles/Ideolog\%EDa\%20y\%20an\%E1lisis\%20del\%20discurso.pdf. Acesso em 10 jan. 2012.

VAN DIJK, T. A. Discurso e Poder. São Paulo: Contexto, 2012.

WEBER, A. Manual on hate speech. Strasburgo: Concil of Europe Publishing, 2009.

ZIMMERMANN, K. Construcción de la identidad y anticortesía verbal. Estudio de conversaciones entre jóvenes masculinos. In: BRAVO, D. (ed.). Estudios de la (des)cortesía en español. Categorías conceptuales y aplicaciones a corpora orales y escritos. Buenos Aires: Dunken, 2005. p. 245-271. 


\section{REFERÊNCIAS DOS VÍDEOS ARGENTINA (AR) E BRASIL (BR)}

Vídeo 1 (V1-AR): CQC. Cacerolaços. 2012. (6m38s). Disponível em: https://www.youtube.com/watch?v=FNlhaBRgygs Caceroleros 13-06-12 CQC 2012. Acesso em: 02. jun. 2016.

Vídeo 2 (V2-AR): TV PÚBLICA. La salvaje agresión al equipo. 2012. (8m31s). Disponível em: https://www.youtube.com/watch?v=r3rR6wADhiQ 678 - La salvaje agresión al equipo de 678. 0306-12. Acesso em: 02. jun. 2016.

Vídeo 3 (V3-AR): PROGRAMA DURO DE DOMAR. Notero obrero en cacerolazo. 2012.(9m15s). Disponível em: https://www.youtube.com/watch?v=b13tY_iUI2E DURO DE DOMAR - NOTERO OBRERO EN CACEROLAZO 8-06-12. Acesso em: 02. jun. 2016.

Video 4 (V4-AR): PROGRAMA DURO DE DOMAR. Cacerolazo vip. 2012. (13m49s). Disponível em: https://www.youtube.com/watch?v=8EjshVs19zM CACEROLAZO VIP. Acesso em: 02. jun. 2016.

Video 5 (V5-AR): CQC. 8N. 2012. (11m53s). Disponível em: https://www.youtube.com/watch?v=5-P110spCH8 CQC 8N. Acesso em: 02. jun. 2016.

Video 6 (V6-AR): INFORME TVR. Las Agresiones del 8N. 2012. (17m49s). Disponível em: https://www.youtube.com/watch?v=WZgxrbd-SoI Las Agresiones del 8N - Informe TVR completo 10 Noviembre. Acesso em: 02. jun. 2016.

Video 1 (V1-BR): TRIP TV. Por favor, chamem o alto comando!. 2015. (5m44s). Disponível em: https://www.youtube.com/watch?t=45\&v=ebzEbjflXkM "Por favor, chamem o alto comando!". Acesso em: 15. jun. 2016.

Vídeo 2 (V2-BR): CARTA CAPITAL. Temos que acabar com os partidos de esquerda. 2015. (3m33s). Disponível em: https://www.facebook.com/video.php?v=907431169278298\&theater 15 de Março: “Temos que acabar com os partidos de esquerda”!”. Acesso em: 15. jun. 2016.

Video 3 (V3-BR): PODEMOS MAIS. Alguém arrisca uma descrição para este vídeo?. 2013. (3m44s). (Disponível em: https://www.facebook.com/video.php?v=386687558169553\&theater Alguém arrisca uma descrição para este vĩdeo?!". Acesso em: 15. jun. 2016.

Video 4 (V4-BR): PODEMOS MAIS. 2013. (0m23s). Disponível em: https://www.facebook.com/video.php?v=385829178255391\&theater!". Acesso em: 15. jun. 2016.

Video 5 (V5-BR): PODEMOS MAIS. Culpa da Dilma ser mulher. 2013. (0m42s). Disponível em: https://www.facebook.com/video.php?v=385959731575669\&theater \#CulpaDaDilma: ser mulher!". Acesso em: 15. jun. 2016.

Video 6 (V6-BR): Disponível em: https://www.youtube.com/watch?v=Nh-_HVETews Manifestação 15 de março - São Paulo - Av Paulista!”. Acesso em: 15. jun. 2016. 
Video 7 (V7-BR): VIMEO. Protesto de olho no "impeachment" de Dilma. 2014. Disponível em: https://vimeo.com/110697471 (1-11-2014) Protesto de olho no "impeachment" de Dilma!". Acesso em: 15. jun. 2016.

Video 8: Disponível em: VIMEO. O impeachment de Dilma na avenida Paulista. 2015. (7m41s). Disponível em: https://vimeo.com/122309721 O impeachment de Dilma na avenida Paulista!". Acesso em: 15. jun. 2016.

Video 9: VIMEO. Disponível em: https://vimeo.com/122309721 O impeachment de Dilma na avenida Paulista!”. Acesso em: 15. jun. 2016. 